\title{
ANALISIS KELAYAKAN USAHA AGROINDUSTRI KRMES (Studi Kasus di Desa Sindangsari Kecamatan Cikoneng Kabupaten Ciamis)
}

\author{
FEASIBILITY ANALYSIS OF THE KREMES AGROINDUSTRY BUSINESS \\ (Case Study in Sindangsari Village Cikoneng District Ciamis Regency)
}

\author{
RESA HAIRUN NISA ${ }^{1}$ *, DINI ROCHDIANI ${ }^{2}$, AGUS YUNIAWAN ISYANTO ${ }^{1}$ \\ ${ }^{1}$ Fakultas Pertanian, Universitas Galuh \\ ${ }^{2}$ Fakultas Pertanian, Universitas Padjadjaran \\ *E-mail: hairunnisaresa7@ gmail.com
}

\begin{abstract}
ABSTRAK
Kremes merupakan makanan ringan yang bahan bakunya terbuat dari ubi kayu. Diharapkan dengan adanya industri pengolahan akan membuat hasil pertanian menjadi suatu produk yang mempunyai nilai tambah dan bernilai ekonomi yang tinggi sehingga mampu meningkatkan keuntungan untuk perusahaan agroindustri kremes. Tujuan dari penelitian ini untuk mengetahui: (1) Besarnya biaya, penerimaan dan pendapatan pada agroindustri kremes di Desa Sindangsari Kecamatan Cikoneng Kabupaten Ciamis dalam satu kali proses produksi, dan (2) Besarnya R/C pada agroindustri kremes di Desa Sindangsari Kecamatan Cikoneng Kabupaten Ciamis dalam satu kali proses produksi. Jenis penelitian yang digunakan adalah studi kasus dengan mengambil kasus di Desa Sindangsari Kecamatan Cikoneng Kabupaten Ciamis. Teknik penarikan sampel secara sengaja (purposive sampling) dan seluruhnya diambil sebagai sampel penelitian atau dilaksanakan sensus. Hasil penelitian menunjukan: (1) Rata-rata biaya total kremes di Desa Sindangsari Kecamatan Cikoneng dalam satu kali proses produksi adalah $\mathrm{Rp} 2.432 .800,1$, sedangkan rata-rata penerimaan adalah $\mathrm{Rp} 3.000 .000,00$ per satu proses produksi, sehingga diperoleh rata-rata pendapatan Rp 567.199,9, dan (2) Rata-rata R/C agroindustri kremes di Desa Sindangsari Kecamatan Cikoneng Kabupaten Ciamis adalah 1,23 artinya setiap biaya yang dikeluarkan 1 rupiah menghasilkan penerimaan 1,23 dan pendapatan 0,23.
\end{abstract}

Kata kunci: Biaya, Penerimaan, Pendapatan, R/C

\begin{abstract}
Kremes was a light meal whose raw materials were made of cassava, hopefully with the processing industry will make agricultural products into a product that has value added and value the high economy so that it was able to increase profitability for the company's agro-industry kremes. The purpose of this research was to know: (1) The amount of cost, acceptance and income in the agroindustry kremes in the Sindangsari Village Cikoneng District Ciamis Regency in one process production, and (2) The amount of $R / C$ on kremes agroindustry in Sindangsari Village Cikoneng District Ciamis Regency in one time production process. Research was done using case study by taking the case in Sindangsari Village Cikoneng District Ciamis Regency. The sample withdrawal technique is intentionally (purposive sampling) and was entirely taken as a sample of research (census). The results showed that: (1) The average total cost of kremes was $R p$ 2, 432,800.1, while the average revenue was $R p$ 3.000.000,00 per one production process, so in gain average profit of $R p$ 567,199.9, and (2) Average $R / C$ was 1.23 meaning that each cost incurred 1 generates a receipt of 1.23 and $a$ profit of 0.23 .
\end{abstract}

Keywords: cost, revenue, income, $R / C$ 


\section{PENDAHULUAN}

Indonesia merupakan negara agraris, ditandai dengan adanya dua musim yaitu musim kemarau dan musim penghujan. Indonesia di mata dunia mempunyai peranan penting dalam hal ini, karena Indonesia sebagai negara agraris yang kaya akan hutan menjadikan Indonesia sebagai paru-paru dunia (Sukino 2013).

Dalam era globalisasi persaingan pasar semakin ketat, dengan sumber daya manusia (SDM) yang unggul akan dapat ditangani dengan baik melalui pemberian harga yang kompetitif terkait dengan peningkatan produktivitas hasil pertanian di pasaran. Dengan demikian, peningkatan sumber daya manusia merupakan kunci sukses, karena pada dasarnya apapun bentuk pembangunan, manusia merupakan pelaku dari kegiatan tersebut. Untuk itu apabila pelaku pembangunan mempunyai sumberdaya yang rendah tentu sangat berpengaruh terhadap hasil pembangunan yang dilakukan (Sukino, 2013).

Menurut Makarawung dkk (2017), pengembangan industri dalam pembangunan dilihat sebagai usaha untuk meningkatkan mutu sumber daya manusia (antara lain untuk meningkatkan produktivitasnya) dan kemampuannya memanfaatkan secara optimal sumberdaya alam dan sumberdaya produksi lainnya.
Fatah (2007), menyatakan bahwa agroindustri merupakan salah satu sistem agribisnis yang berperan penting dalam paradigm baru karena dapat meningkatkan distribusi pendapatan.

Kecamatan Cikoneng merupakan salah satu sentra industri pengolahan hasil pertanian ketujuh terbesar di Kabupaten Ciamis, memiliki tiga sentra industri pengolahan hasil pertanian, yaitu sentra makanan ringan, sentra kue kering, dan sentra kerupuk dengan jumlah unit usaha sebanyak 106 unit, Makanan ringan di Kecamatan Cikoneng sangat beranekaragam, salah satunya adalah kremes.

Kremes merupakan makanan ringan yang bahan bakunya terbuat dari ubi kayu. Usaha kremes di Kecamatan Cikoneng tersebar di beberapa desa, salah satunya di Desa Sindangsari yang memiliki 2 agroindustry kremes. Desa Sindangsari adalah tempat perusahaan kremes yang memiliki jumlah produk yang terbanyak dibandingkan dengan desa lain, diharapkan dengan adanya industri pengolahan akan membuat hasil pertanian menjadi suatu produk yang mempunyai nilai tambah dan bernilai ekonomi yang tinggi sehingga mampu meningkatkan keuntungan perusahaan agroindustri kremes itu. Besarnya keuntungan yang diterima dapat 
digunakan sebagai tolok ukur dalam melihat perkembangan agroindustri kremes dalam jangka panjang. Diharapkan dengan adanya agroindustri ini dapat mengurangi pengangguran dan memperluas lapangan kerja. Untuk memperoleh keuntungan dari suatu kegiatan produk tidak terlepas dari pengeluaran sebagai biaya yang digunakan dalam kegiatan produksi. Untuk mengetahui suatu perusahaan menguntungkan atau tidak, maka perlu dilakukan adanya analisis mengenai biaya, penerimaan, pendapatan dan $\mathrm{R} / \mathrm{C}$.

Tujuan dari penelitian ini untuk mengetahui: (1) Besarnya biaya, penerimaan dan pendapatan pada agroindustri kremes di Desa Sindangsari Kecamatan Cikoneng Kabupaten Ciamis dalam satu kali proses produksi, dan (2) Besarnya R/C pada agroindustri kremes di Desa Sindangsari Kecamatan Cikoneng Kabupaten Ciamis dalam satu kali proses produksi.

\section{METODE PENELITIAN}

Jenis penelitian yang digunakan adalah studi kasus dengan mengambil kasus di Desa Sindangsari Kecamatan Cikoneng Kabupaten Ciamis. Menurut Sujarweni (2018), studi kasus bertujuan untuk mengembangkan metode kerja paling efisien, maknanya peneliti mengadakan telaah secara mendalam, kesimpulan hanya berlaku atau terbatas pada kasus tertentu saja.

Data yang digunakan dalam penelitian ini terdiri atas data primer dan sekundern. Data primer diperoleh dengan observasi dan wawancara langsung terhadap responden dengan menggunakan daftar pertanyaan yang dipersiapkan sebelumnya. Data primer yang digunakan dalam penelitian ini adalah data-data biaya, penerimaan dan pendapatan agroindustry. Data sekunder, yaitu data yang diperoleh dari instansi-instansi yang ada kaitannya dengan penelitian ini.

Desa Sindangsari Kecamatan Cikoneng dipilih secara sengaja (purposive sampling) sebagai lokasi penelitian. Terdapat dua agroindustri di desa tersebut sehingga semuanya diambil sebagai sampel penelitian atau dilaksanakan sensus.

Biaya yang dikeluarkan pada agroindustri kremes dihitung dengan persamaan berikut (Soekartawi, 2002):

$\mathrm{TC}=\mathrm{TFC}+\mathrm{TVC}$

Dimana:

$\mathrm{TC}=$ Total Cost (Biaya total)

TFC = Total Fixed Cost (Biaya Tetap Total)

TVC = Total Variable Cost (Biaya

Variabel Total) 
Menurut Rahim dan Hastuti (2007), penerimaan adalah perkalian antar produksi yang diperoleh dengan harga jual. Penerimaan dihitung dengan menggunakan persamaan berikut:

$\mathrm{TR}=\mathrm{Y} . \mathrm{Py}$

Dimana:

$\mathrm{TR}=$ Total Penerimaan

$\mathrm{Y}=$ Produksi yang diperoleh

Py = Harga Produk

Menurut Rahim dan Hastuti (2007), pendapatan merupakan selisih antara penerimaan dan semua biaya. Dengan kata lain, pendapatan meliputi pendapatan kotor atau penerimaan total dan pendapatan bersih, dan dihitung dengan persamaan berikut:

$\mathrm{Pd}=\mathrm{TR}-\mathrm{TC}$

$\mathrm{TR}=\mathrm{Y} . \mathrm{Py}$

$\mathrm{TC}=\mathrm{FC}+\mathrm{VC}$

Dimana:

$\mathrm{Pd}=$ Pendapatan

$\mathrm{TR}=$ Total Revenue $($ Penerimaan Total $)$

$\mathrm{TC}=$ Total Cost (Biaya Total)

Menurut Rahim dan Hastuti (2007),

$\mathrm{R} / \mathrm{C}$ adalah perbandingan antara penerimaan dengan biaya, dan dihitung dengan persamaan berikut:

$\frac{R}{C}=\frac{\text { Penerimaan Total }}{\text { Biaya Total }}$

Dimana:

Revenue $=$ Penerimaan

Cost = Besarnya biaya yang

dikeluarkan

Dengan ketentuan: a. Apabila $\mathrm{R} / \mathrm{C}>1$, maka agroindustri kremes tersebut menguntungkan.

b. Apabila $\mathrm{R} / \mathrm{C}=1$, maka agroindustri kremes tersebut tidak untung tidak rugi.

c. Apabila R/C < 1, maka groindustri kremes tersebut merugikan.

\section{HASIL DAN PEMBAHASAN}

\section{Identitas Responden}

Umur responden berada pada kisaran usia produktif (15-64 tahun). Hal ini sesuai dengan pendapat Wirosuharjo (2004) yang menyatakan bahwa umur produktif antara 15 sampai 64 tahun. Tingkat pendidikan responden adalah lulusan Sekolah Dasar (SD) dan S1. Jumlah tanggungan keluarga responden berkisar 2-3 orang.

Pengalaman berusaha dari responden adalah selama 5 tahun. Menurut Soekartawi (2006), pengalaman dan pengetahuan yang dimiliki seseorang pada umumnya akan mempengaruhi proses pengambilan keputusan. Berdasarkan pengalaman, pengusaha akan menggunakan faktor produksi untuk mendapatkan pendapatan yang lebih baik.

\section{Analisis Biaya pada Agroindustri Kremes}

Biaya yang digunakan dalam usaha agroindustri kremes dibagi menjadi dua jenis biaya, yaitu biaya tetap dan biaya 
variabel. Biaya tetap yaitu biaya yang besar kecilnya tidak dipengaruhi oleh besar kecilnya produksi, yang terdiri dari penyusutan alat, pajak bumi dan bangunan, izin usaha, NPWP dan Bunga Modal. Sedangkan biaya variabel adalah biaya yang besar kecilnya dipengaruhi oleh besar kecilnya produksi yang terdiri atas biaya penyediaan bahan baku (sarana produksi), dan tenaga kerja. Biaya yang dikeluarkan oleh pengusaha kremes di Desa Sindangsari dapat dilihat pada Tabel 1.

Tabel 1. Analisis Biaya

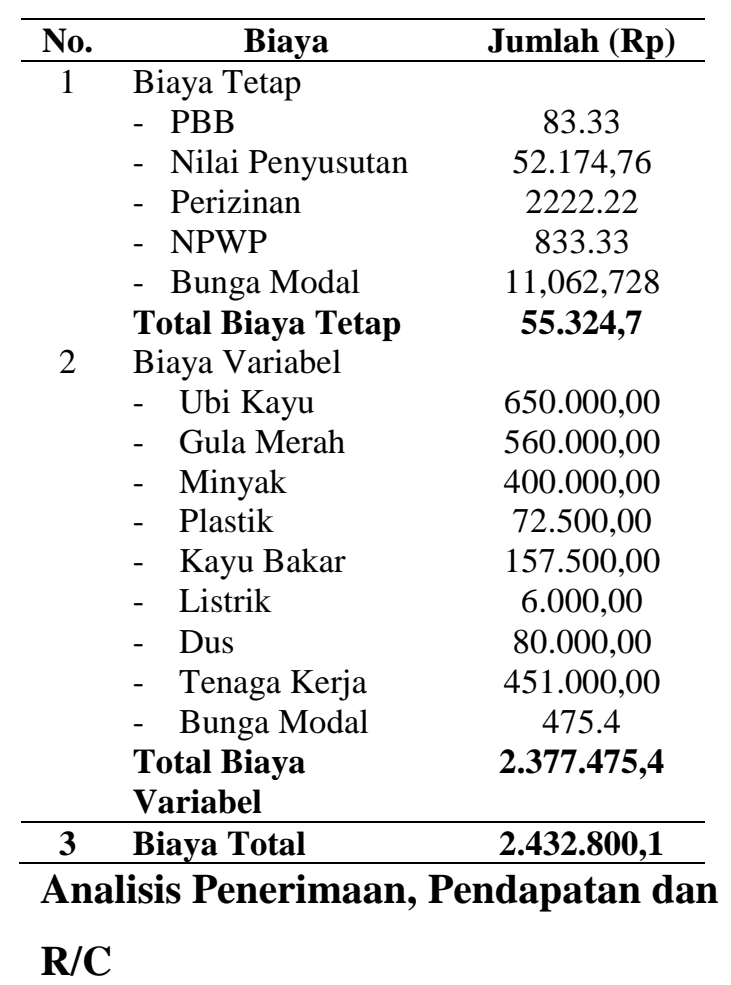

Penerimaan merupakan hasil perkalian dari volume produksi dengan harga jual yang berlaku pada saat penelitian. Jumlah produk kremes yang dihasilkan dalam satu kali proses produksi sebanyak 100 dus dengan harga jual Rp
30.000,00 per dus, sehingga penerimaan sebesar Rp 3.000.000,00.

Pendapatan merupakan selisih penerimaan dengan biaya dalam satu kali proses produksi. Penerimaan agroindustri kremes $\quad \mathrm{Rp}$ 3.000.000,00 sedangkan biayanya $\operatorname{Rp} 2.432 .800,1$, sehingga pendapatan dalam satu kali proses produksi sebesar Rp 567.199,9.

Kelayakan usaha agroindustri kremes di Desa Sindangsari Kecamatan Cikoneng Kabupaten Ciamis didekati dengan menggunakan R/C. R/C pada agroindustri kremes di Desa Sindangsari sebesar 1,23 sehingga layak untuk diusahakan. R/C sebesar 1,23 menunjukkan bahwa dari setiap biaya yang dikeluarkan sebesar Rp 1 akan menghasilkan penerimaan $\mathrm{Rp}$ 1,23 dan pendapatan $\operatorname{Rp} 0,23$.

Tabel 2. Rata-rata jumlah produksi kremes dalam satu kali proses produksi.

\begin{tabular}{clr}
\hline No. & \multicolumn{1}{c}{ Uraian } & Jumlah \\
\hline 1 & Produksi kremes (dus) & 100 \\
2 & Harga produk (Rp/dus) & $30.000,00$ \\
3 & Total penerimaan(Rp) & $3.000 .000,00$ \\
4 & Penerimaan & $3.000 .000,00$ \\
5 & Biaya total & $2.432 .800,1$ \\
6 & Pendapatan & $567.199,9$ \\
7 & R/C & 1,23 \\
\hline
\end{tabular}

\section{KESIMPULAN DAN SARAN}

\section{Kesimpulan}

1) Rata-rata biaya pada agroindustri kremes di Desa Sindangsari Kecamatan 
Cikoneng dalam satu kali proses produksi sebesar Rp 2.432.800,1, sedangkan rata-rata penerimaan $\mathrm{Rp}$ 3.000.000,00 per satu proses produksi, sehingga diperoleh rata-rata pendapatan Rp 567.199,9.

2) Rata-rata R/C kremes di Desa Sindangsari Kecamatan Cikoneng Kabupaten Ciamis adalah Rp 1,23 artinya dari setiap biaya yang dikeluarkan sebesar $\mathrm{Rp} 1$ akan menghasilkan penerimaan $\mathrm{Rp}$ 1,23 dan pendapatan $\mathrm{Rp} 0,23$.

\section{Saran}

Agroindustri kremes disarankan untuk meningkatkan usahanya yaitu dengan meningkatkan volume produksinya (skala usahanya) agar keuntungannya dapat meningkat.

\section{DAFTAR PUSTAKA}

Fatah, L. 2007. The Potentials of AgroIndustry for Growth Promotion and Equality Improvement in Indonesia. Asian Journal of Agriculture and Development, 4(1): 57-74.

Makarawung, V,. Pangemanan , P. A,. dan Pakasi C.B. 2017. Analisis Nilai Tambah Buah Pisang Menjadi Keripik pada Industri Rumah Tangga di Desa Membe Kecamatan Membe. Agro-Sosioekonomi: Jurnal Ilmiah Sosial Ekonomi Pertanian, 13(2A): 83-90.

Rahim, A., \& Hastuti, D. R. D. 2007. Pengantar Teori dan Kasus Ekonomika Pertanian. Jakarta: Penebar Swadaya.

Soekartawi. 2002. Analisis Usaha Tani. Jakarta: Universitas Indonesia (UIPress).

Soekartawi. 2006. Analisis Usaha Tani. Jakarta: Universitas Indonesia (UIPress).

Sujarweni. 2018. Metodelogi Penelitian. Yogyakarta: Pustaka Baru Press.

Sukino. 2013. Membangun pertanian dengan pemberdayaan masyarakat tani: terobosan menanggulangi kemiskinan. Pustaka Baru Press.

Wirosuharjo. 2004. Dasar-Dasar Demografi. Jakarta: Fakultas Ekonomi Universitas Indonesia. 